\title{
Enabling the mapping of Internet of Things ecosystem business models through roles and activities in value co-creation
}

\author{
Heini Ikävalko \\ Aalto University \\ heini.ikavalko@aalto.fi
}

\author{
Petra Turkama \\ Aalto University \\ petra.turkama@aalto.fi
}

\author{
Anssi Smedlund \\ Aalto University \\ anssi.smedlund@aalto.fi
}

\begin{abstract}
The increasing connectivity provided by the Internet of Things (IoT) supports novel business opportunities for actors' overlapping service systems. Therefore, the co-creative nature of IoT business needs to be further studied. This paper contributes to the understudied area of IoT ecosystem dynamics by reporting an empirical study on a European IoT initiative and describing different actor roles and activities in the IoT use cases, and their implications for IoT ecosystem value creation. The paper shows how IoT ecosystem actors may take the roles of Ideator, Designer, or Intermediary in different design layers, and, recommends this approach to better understand and describe ecosystem business models. Theoretical and managerial implications are discussed.
\end{abstract}

\section{Introduction}

The Internet of Things (IoT) has spawned emerging business opportunities as digital technology is being embedded in objects that have never been connected before [1]. The IoT is by general definition related to physical or virtual devices capable of sending and receiving information in real time [2]. IoT data are used in constructing a virtual counterpart of reality that can be used in optimization, prediction and control [3], [4]. The IoT further offers new business opportunities through novel services for example in the domains of transportation and logistics, healthcare, smart environments and personal domains [5].

Business models are significant in a firm's success as they provide structured tools for management [6]. Business models have been defined as "simplified and aggregated representation of the relevant activities of a company" [7]. Evidence of the significance and increasing interest in the business model concept in general is shared by both practitioners and academics [7]. Nonetheless, research on IoT business models remains limited. A few empirical studies hint at the increased relevance of customer and partner relationships [7]. Further, previous developments in IoT discussions suggest a shift towards an ecosystem perspective in the IoT context [1], [8], [9]. An ecosystem business model is "composed of value pillars anchored in ecosystems and focuses on both the firm's method of creating and capturing value as well as any part of the ecosystem's method of creating and capturing value"[8]. This emerging ecosystem perspective differs from the firm-level perspective on business models, emphasizing the characteristics of IoT ecosystems.

An important characteristic of the IoT is the complexity it entails. Compared to the pre-IoT era, in which information systems were designed and built for a specific purpose at a given time, in IoT ecosystem data, the analytics of using the data, as well as the outputs of the data, are ex-ante unknown. Thus IoT ecosystems satisfy the general definition of complexity [10] where the actors follow their own control logics, and the interactions among them are not pre-defined. The complexity of IoT business further refers to ecosystem based business models, whereby the actors' business models are inter-dependent. Challenges include a wide variety of objects, immaturity of innovation and the unstructured nature of ecosystems [8], which makes it difficult to identify and exploit the business opportunities of the ecosystems.

Opportunities of the IoT ecosystems, on the other hand, include creating a higher level of synergy and efficiency through the connectivity of several service systems. In this system of systems, different service systems overlap with each other. This implicates all partners in service creation, and the roles of service providers and users vary. Even greater benefits can be attained through implementing open standards that enable full scalability of developed models, and exploitation of created value. Open source software (OSS) technologies have been considered the major driver for scalability of innovations [11]. Related business models rely on approximation and 
complementarity to other resources like human capital or proprietary products and services. This can include supply of support personnel, user toolkits, coordination functions or virtual communities [12], [13]. Technical concerns in different industry sectors and usage areas have been reported to be increasingly assimilated, and thus the same general enabling technologies and solutions can be used in a variety of application areas. Despite the rapid maturing of the technologies, their commercial adaptation remains limited. Consequently, the literature on customer value creation in OSS is still very new and few authors have addressed the creation of value in the OSS development model, with the exception of West [14] and Morgan \& Finnegan [11]. The main limitations include technical barriers like interoperability, application programming interface (API) compatibility and integration challenges. There are also numerous non-technical challenges like business continuity, reliability and continued support of technologies.

This paper is motivated by the aforementioned challenges and opportunities of IoT ecosystems and the paucity of empirical research in this area. Recent work on IoT ecosystem business models notes the change from providing products to services [9] and the relevance of service-dominance logic [1] and provide elements to draw upon. The framework by Turber et al. [1] note the digital layeredness of IoT, but does not discuss in more detail the role of collaborators in value creation. Further, Iivari et al. [9] argue for the relevance of co-creation and co-capture, but stay at the conceptual level in their work.

This paper argues that, in order to realize the potential of the IoT ecosystem business opportunities, the relevant actors, relationships and activities need to be mapped. With the aim of understanding IoT ecosystem business models, this paper seeks to contribute by addressing the following research question: How do different actors contribute to the IoT ecosystem cocreation? We extend the earlier literature by differentiating the roles of IoT ecosystem partners in service co-creation. The paper deepens the business model discussion by suggesting the archetype roles of Ideator, Designer, and Intermediator to be used in the ecosystem business model mapping. Our study provides an empirical illustration of the variety of actor roles, their reasons to participate and activities in IoT ecosystems, thus contributing to the IoT ecosystem management and business model discussion. This paper shows how different roles relate to ecosystem value creation and earning logic. Actors' IoT ecosystem business models are extensions to their prevailing business models, building on jointly created value.
The paper is structured as follows. First, we review the relevant literature concerning IoT ecosystem business models and value co-creation. Second, we describe the methodology of the study. Then, the results section describes with what activities and in which roles the different actors in the case contribute to the IoT ecosystem value co-creation. The results are then discussed with both theoretical and managerial contributions.

\section{Literature review}

\subsection{IoT ecosystem business models}

Despite the multifaceted nature of the concept business model [7], [15], the concept provides a suitable base for mapping the activities of IoT ecosystems. Of the different business model definitions, we build on those that refer to the business model as relevant activities [16] or as conceptual tool expressing the underlying business logic [17]. Therefore, in this paper we refer to the business model as "a simplified and aggregated representation of the relevant activities of a company" [7].

Literature on business models has developed from a product-level and processes-focus towards a broader view, with an increasing interest in strategic and company or industry-level orientation [7]. Along with the current digital development, the focus shifts more to the level of ecosystems. The complexity of the IoT and the layered architecture of digital technology [18] also change the business model orientation [8], [9]. Key concerns over the ecosystem perspective crystallize in these three questions: Who are the collaborators? Why do they participate? Where are the sources of value creation? [1].

In addition to the practical [19] or conceptual [9] interest in IoT business models, empirical investigations have looked at the elements of the IoT business models and their importance. Of the different business model elements, the role of value proposition appears undeniably important both in light of empirical [4], [20] or theoretical [1] approaches. Empirical findings concerning value proposition highlight convenience, performance, 'getting the job done', possibility for updates, or ease of use [4]. Concerning the role of cost reduction, the findings are still somewhat contradictory. Although experts have suggested that cost reduction is not enough for IoT value proposition, it still plays a significant role among companies [4].

The change in the role of data in the IoT business models is one of the major shifts taking place [19]. For example, a study by $\mathrm{Ju}$ et al. [20] emphasized the crucial role of the sensor data and consequently, the 
analytical capabilities required to create competitive advantage of the data. Consequently, the four layers of the digital architecture [18] provide sources for value creation in the Iot context, answering the question Where [1]. Thus, value can be created on 1) device layers (consisting of physical layers such as hardware and logical capability layers such as operating system), 2) network layers (consisting of physical transport layers such as cables and logical transmission layers such as network standards), 3) service layer, and 4) content layer [18]. In this paper, we follow Turber et al. [1] who suggest analyzing the IoT ecosystem value creation in these four layers of digital architecture.

\subsection{Value co-creation in IoT ecosystems}

The empirical studies on IoT business models show how the key partners, building blocks in the IoT, create complexity in the business model by bringing about a strong outsourcing component. The importance of software and app developers, launching customers, hardware and data analysis partners show the outsourcing of crucial activities [4]. This underscores the need for shared interest in and understanding of other partners' revenues [4], [19]. This illustrates the shift from firm-centricity to network-centricity in the activity, which has been suggested along with the change to S-D logic in IoT [1]. This highlights the ecosystems' character of business in IoT context and the need to consider business models at the level of ecosystems instead of single firms [9].

The ecosystem concept plays an increasingly important role in the management of innovation and technology, with various definitions [41]. The term business ecosystem has been widely used to refer to a community of interacting firms and individuals who co-evolve their capabilities and roles, and tend to align themselves with the directions set by one or more central companies [21], [22]. A platform ecosystem is a specific part of the business ecosystem consisting of a platform owner, its complementors and end-users [23]. Further, knowledge ecosystems, with universities and other research institutes playing strong roles, have as their main interest creating new knowledge [24]. The motivation of ecosystem partners can include economic, societal or self-actualization as drivers for participation. Literature on innovation ecosystems has incorporated both production and use side participants in developing new value through innovation [25]. Lusch and Nambisan [26] refer to service ecosystem as "a relatively self-contained, self-adjusting system of mostly loosely coupled social and economic (resource-integrating) actors connected by shared institutional logics and mutual value creation through service exchange". All these different ecosystem perspectives contribute to understanding IoT ecosystems, which may include the aforementioned aspects.

Recent theorizing identifies two different perspectives on ecosystems, ecosystems-as-affiliation or ecosystems-as-structure [27]. While the ecosystem as affiliation builds typically on a focal firm and its ties with other actors, ecosystem as structure starts with a value proposition and only then considers the actors and activities and their required alignment [27]. Following the latter perspective, we refer to ecosystem as "the alignment structure of the multilateral set of partners that need to interact in order for a focal value proposition to materialize" [27]. This definition takes an activity-centric approach and focuses on the configurations of activity defined by a value proposition [27]. This definition fits better with the nature of IoT ecosystems, in which building ecosystems around a focal actor is no longer the only solution for ecosystems.

As the customers become collaborators through co-creation, the meaning of value proposition broadens to take into account not only customerspecific value creation, but also other collaborators' reasons for ecosystem participation [1]. Answering the question Why? leads to inclusion of both monetary and non-monetary benefits, thus increasing the complexity of ecosystem business model. Customer relationships in IoT business models build on co-creation and communities, thanks to the quick and personalized customer contact enabled by access to the customer data [4], [19].

Despite acknowledging the relevance of joint value co-creation of IoT ecosystems [9], the current literature lacks further conceptualizing and empirical studies of the variety of roles in IoT ecosystem value co-creation. Instead of simply describing who are the collaborators, we apply the differentiation of roles in service co-creation, which Lusch and Nambisan [26] discuss in their conceptual paper of digitally enabled service innovation.

Value co-creation is essentially interactions between a firm and its customers [28]-[30], but can include also other parties, such as, suppliers, business partners or competitors [31]. In light of service science's service dominant logic (S-D logic), value is always co-created when capabilities, or specialized human knowledge and skills are being applied for the benefit of the recipient [32], [33]. S-D logic assumes that service is exchanged for service, and even a seemingly passive recipient still provides input for the value co-creation relationship. 
The recipient is the beneficiary of the value cocreation, and according to recent conceptualization, the beneficiary can play many different roles [26]. By classifying the roles into three categories, it is possible to understand how value co-creation differs based on how the actor is oriented towards service innovation in the ecosystem of various actors [26]. Defining the company's ecosystem role lays the foundation and defines the options for the company's business model design. The assumed role further expresses the service exchange logic between the ecosystem partners.

Firstly, Ideators integrate current market offerings with their unique contexts and needs and provide input for service innovation by explicating these needs to the ecosystem with one-way communication. Secondly, Designers mix and match existing knowledge components to develop new services with the ecosystem with reciprocal communication. Thirdly, Intermediaries cross-pollinate knowledge across many ecosystems and orchestrate service innovation with multi-way communication, affecting both the flow of knowledge and relationships [26], [34]. The intermediary role is especially highlighted, since the intermediaries act as orchestrators designing and facilitating the processes that allow ecosystem actors to collaborate with each other [35]. Table 1 further illustrates the definitions of the three roles.

Table 1: Service exchange roles in loT ecosystems. Adapted from [26], [34]

\begin{tabular}{|l|l|l|}
\hline Role & Definition & \\
\hline Ideator & $\begin{array}{l}\text { Bring knowledge about own } \\
\text { needs to the ecosystem. One- } \\
\text { way knowledge flows. Providing } \\
\text { input for service innovation. }\end{array}$ & \\
\hline Designer & $\begin{array}{l}\text { Mix and match existing } \\
\text { knowledge components in the } \\
\text { ecosystem. Reciprocal } \\
\text { knowledge flows. Developing } \\
\text { service innovation. }\end{array}$ & \\
\hline Intermediary & $\begin{array}{l}\text { Intermediate flow of knowledge } \\
\text { and relationships in the } \\
\text { ecosystem. Multi-way } \\
\text { knowledge flow, orchestrating } \\
\text { service innovation. }\end{array}$ & \\
\hline
\end{tabular}

To summarize our perspective, we build on the work of Turber et al. [1], Lusch and Nambisan [26], Smedlund and Toivonen [34] and, Adner [27], and define an IoT ecosystem business model as internet mediated activities among the service co-creation actors and connected smart objects, aligned for creating and capturing value both for each role in service exchange and for a shared purpose. Figure 1 captures the key elements for mapping the IoT ecosystem business model.

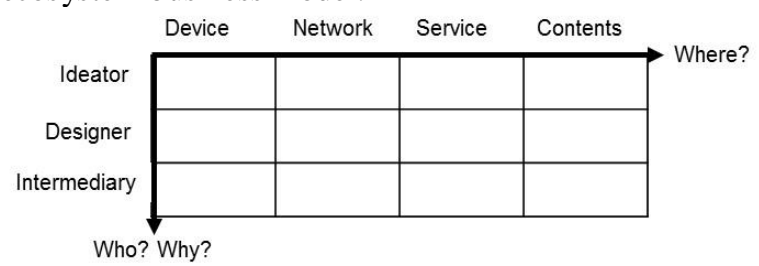

Figure 1: Key elements for loT ecosystem role mapping

\section{Methodology}

Our study employs a multiple-case study design, which supports the goal of illuminating and extending the relationships of the research topic with a more accurate and better-grounded approach [36]. Relying on theoretical sampling [37] we selected cases that can extend the emergent theory. The cases represent evolving IoT ecosystems in a European Commission H2020 funded initiative [38].

The case context for this study is a project called bIoTope, Building IoT Open Innovation Ecosystems. The overall objective of the bIoTope project (20162018 ) is to strengthen and accelerate innovation and impact creation capacities for European companies and public agencies. This is achieved through concept validation in experimental large-scale, real life pilots. The project seeks to build a European alternative to the solutions by the dominant American companies, building on open standards and distributed value creation models. The novelty of these models makes them valuable and interesting topics of research. Each pilot features Use Cases that represent different crosssectorial IoT enabled services. In the first phase the pilots build minimum viable products (MVP) on each use case for the proof of concept. In the second phase the Use Cases are expanded with new partners through Open Call procedure, and further validated for business sustainability through business model and exploitation planning.

The three use cases selected represent open standard based IoT ecosystems in smart city context in European cities: Brussels, Helsinki and Lyon. The cities acted as pilots in the bIoTope project, in which the authors act as researchers. The project builds on a triple-helix collaboration model involving partners from cities, public agencies, as well as both small and large companies. The ongoing research project context gave us access to the ecosystems and their actors, thus providing us with a rich dataset. Qualitative data was collected for one year, mainly by participatory observation, co-working and document reviews. The data consists of company documentation, project 
documentation, meetings with project partners, project meetings and the presentations and informal discussions during the meetings.

In order to grasp the IoT ecosystem activities and different actors' roles in the value creation, we started mapping the IoT ecosystem business models by use case illustrations. According to Lambert and Davidson [39], a business model as a unit of analysis is especially useful in cases "where the success of the organization is closely tied to the relationships the entity has with others in the network". For the project partners, the project deliverables on use case descriptions served as a tool for making sense of the ecosystem activities. For the purpose of this research, we mapped the cases according to the ecosystem business model dimensions described in the literature review (role, motivation, digital layer). After this within-case analysis, we proceeded to cross-case analysis for verification of the results, triangulation of data and identification of patterns. We summarized our findings concerning the service co-creation roles, and reflected back to their relation to the corresponding business models.

\section{Results}

This chapter describes each use case following the adopted methodology and analyzes the findings in relation to earlier knowledge and discusses the generalizability of the findings.

\subsection{Case 1. Brussels / Safe school journey}

The aim of the bIoTope Brussels IoT ecosystem is to ensure the safety of children commuting to school in the city of Brussels. The daily commuting of children to and from the schools effects and is effected by the surrounding traffic management, including extent of traffic, traffic lights, speed limits and routing of delivery and emergency vehicles. The IoT ecosystem can connect the different sources of information and enable a smooth and safe school commuting experience for the children and their parents by traffic optimization e.g., through using dynamic traffic lights, informing drivers of school hours and, organizing co-mobility of children with the assistance of a mobile application. The developed platform builds on open standards, which further allows for scalability to further services in the future. The main actors in the case are the children and their parents, schools, the regional IT agency, CIRB, Telecom Agency Orange, traffic administration for the region, Brussels Mobility, and companies offering mobile application and web site development as well as big data analytics (Waze, BeMobile, Cityzendata, Holonix).

Ideators in this case are school children who use a mobile application and volunteer their location data in exchange for service. They operate in the content layer, bringing their context specific request for service to the other actors in the ecosystem. They are motivated by non-monetary reasons such as increased safety and fun through the gamification of the app and social motivators of treating the school journey as a group exercise. Their parents participate in the ecosystem by buying the application for their children and thus facilitating boundary crossing and acting as intermediary. Since their action is directly related to the end device, action takes place on the device layer.

The participating schools have a dual role as ideators and intermediaries. As ideators, the school actors play a central role in orchestrating the activities and communicating needs to developers. In their role as intermediary, they facilitate the exporting and importing of knowledge across boundaries. Their level of contribution to the ecosystem is at the service and contents levels, as they operate with data and knowledge. Their value proposition comes in a nonmonetary form, as increased safety around their school and improved safety awareness.

A telecom operator (Orange) and data operators (Waze, BeMobile) as well as the company providing data analytics (Cityzen Data) act as ideators in the content layer. Orange provides information about the global flow of people in the Brussels Capital region around the schools, thus making it possible to address the app-users' needs. Consequently, Waze and BeMobile provide information about data flows concerning, e.g. the current local traffic situation. Cityzen Data provides the analysis of the data provided by the mobile application and other sources (e.g. traffic information), thus making the knowledge embedded in data explicit for service providers. They all share a monetary motivation and are compensated for their work.

Another company (Holonix) develops the application for school kids to use during their school commute. Acting as designer, it develops the graphical user interface as a commercial service at the device layer and mixes and matches existing knowledge components and develops new services. The University of Luxembourg acts in the role of designer on the network and content layers. The university enables the data flow in the network by enabling system interoperability through O/MI-O/DF wrapper connection to the API.

The regional IT agency (CIRB) collects and sends all the information to a central database in order to create a historical database in the IoT ecosystem. 
Acting on the network layer it acts in an intermediary role, as it exports and imports knowledge across ecosystem actors with the open API. Brussels Mobility acts as an intermediary in the ecosystem, providing the sensors and traffic data on both the network and content layers. Table 2 summarizes the actors' roles and layers of their contribution.

Table 2. Roles and layers in Brussels use case

\begin{tabular}{|l|l|l|l|l|}
\hline & Device & Network & Service & Contents \\
\hline Ideator & & & $\begin{array}{l}\text { School, } \\
\text { Child- } \\
\text { ren }\end{array}$ & $\begin{array}{l}\text { Schools, } \\
\text { Children, } \\
\text { Orange, } \\
\text { Waze, } \\
\text { BeMobile } \\
\text { CityzenData }\end{array}$ \\
\hline Designer & Holonix & $\begin{array}{l}\text { Univ. of } \\
\text { Luxem- } \\
\text { bourg }\end{array}$ & Holonix & $\begin{array}{l}\text { Univ. of Luxem- } \\
\text { bourg }\end{array}$ \\
\hline $\begin{array}{l}\text { Inter- } \\
\text { mediary }\end{array}$ & Parents & $\begin{array}{l}\text { ClRB } \\
\text { Brussels } \\
\text { Mobility }\end{array}$ & & $\begin{array}{l}\text { Schools } \\
\text { Brussels } \\
\text { Mobility }\end{array}$ \\
\hline
\end{tabular}

\subsection{Case 2. Lyon / Sustainable bottle bank management}

The aim of the bIoTope Lyon IoT ecosystem is to provide a sustainable waste management service in the Lyon region. The use case concerns bottle banks and optimization of the collecting of the bottles and routing of the collection trucks. Previously, data on the emptying frequency and routes of the trucks were managed by the collection companies themselves. Now, the IoT ecosystem aims to use the sensor data from the bottle banks to optimize the routes and timing for the collectors, as well as provide a cleaner environment and less environmental impact around the bottle banks. The system can be scaled to include additional services, like weather alerts, festivals and events, traffic information and alarms. The main actors in the IoT ecosystem are: citizens as users of the bottle banks, the regional mobility actor in the metropolitan area of Lyon (Métropole de Lyon), municipal IT operator Data Grand Lyon, and the bottle bank collection company.

The value proposition for the citizens demonstrates itself in the form of improved service through better bottle bank information, as well as better quality of life resulting from a cleaner, less polluted and less noisy city. The citizen activities lay on the content level as they, by using the bottle banks, create data in the IoT ecosystem, thus acting in the role of ideator in service co-creation.

The city actor, Métropole de Lyon, has multiple motivations for participating. Monetary motivation arises from the possibility of saving money through cost reduction of waste management, and application of additional services for the created platform. Nonmonetary reasons include improving quality of life for citizens. The city actor has a dual role as ideator and intermediary. It provides both the sensors in the bottle banks as well as a metropolitan data platform for sharing information about e.g., bottle bank location and traffic information, thus acting as intermediary. It also orchestrates collaboration among parties as the case owner. The ideator role is demonstrated through contribution to knowledge conversion both in the network and content layers.

Data Grand Lyon is the city owned IT provider for the internet infrastructure. It develops the O/MI-O/DF wrapper connection to the API provided by the route optimizer. Thus, it acts as intermediary in the network layer, enabling data traffic.

The designers in this case are the truck company providing collection services and the company providing route-optimizing services for them as subcontractor. They both contribute to the ecosystem by developing services by mixing and matching knowledge components. Their motivation to participate in the ecosystem is monetary-driven as they are financially compensated for their tasks. Their activities contribute to the service-level. Table 3 summarizes the actors' roles and layers of their contribution.

Table 3. Roles and layers in Lyon use case

\begin{tabular}{|l|l|l|l|l|}
\hline & Device & Network & Service & Contents \\
\hline Ideator & & $\begin{array}{l}\text { Métropol } \\
\text { e de } \\
\text { Lyon }\end{array}$ & $\begin{array}{l}\text { Citizens } \\
\text { Métropole } \\
\text { de Lyon }\end{array}$ \\
\hline Designer & $\begin{array}{l}\text { Truck } \\
\text { company }\end{array}$ & $\begin{array}{l}\text { Data } \\
\text { Grand } \\
\text { Lyon }\end{array}$ & $\begin{array}{l}\text { Truck } \\
\text { company } \\
\text { Route } \\
\text { optimizer }\end{array}$ & $\begin{array}{l}\text { Data Grand } \\
\text { Lyon }\end{array}$ \\
\hline $\begin{array}{l}\text { Inter- } \\
\text { mediary }\end{array}$ & & $\begin{array}{l}\text { Data } \\
\text { Grand } \\
\text { Lyon }\end{array}$ & $\begin{array}{l}\text { Métropole } \\
\text { de Lyon }\end{array}$ \\
\hline
\end{tabular}

\subsection{Case 3: Helsinki / Promoting the use of electronic vehicles}

The overall aim of the bIoTope Helsinki IoT ecosystem is to promote citizen use of electronic vehicles (EV). The use case focuses on the charging of electronic vehicles, because the lack of a charging infrastructure currently is one of the major use barriers. The few existing charging service providers have their proprietary systems (authentication, payment, booking, etc.), which are not connected with car manufacturer or city systems and platforms. In 
Finland, the existing electrical infrastructure for preheating cars in winter provides an underutilized opportunity for a slow charging service. To tackle the challenge, the aim of the project is to create a Systems of Systems (SoS), which connects information from different sources and provides interoperability between different service suppliers through a common standard. The system is labeled IoTBnB, since the vision for the system is to ultimately grow into an Airbnb-type service system with independent providers posting their services, and include additional ancillary services. The main actors in the case are the city, represented by municipal innovation agency Forum Virium and IT operator Helsinki Region Infoshare, EV users and EV charging stations, Aalto University, and a company providing data analytics, ControlThings.

The city actor Forum Virium acts as an ideator in the case. Forum Virium initiated the case, and articulated the user need in conceptual and content layers. The EV users act as user-developers, providing service providers with their personal data on EV use in the content layer. The EV charging providers broadcast their data to the IoTBnB in content and service layers.

ControlThings is a company that provides an IoT service catalogue (IoT BnB) for the IoT ecosystem, acting as designer in the service and device layers. Aalto University acts as designer as they make the O/MI-O/DF wrapper that connects all the information within the ecosystem, combining content to the network. The Helsinki Region Infoshare, municipal digital services provider, acts as intermediary in the network level, by offering a dashboard and sharing the information concerning the charging stations. Table 4 summarizes the actor roles and layers of their contribution.

Table 4. Roles and layers in Helsinki use case

\begin{tabular}{|l|l|l|l|l|}
\hline & Device & Network & Service & Contents \\
\hline Ideator & & & $\begin{array}{l}\text { City of } \\
\text { Helsinki } \\
\text { Charging } \\
\text { service } \\
\text { provider }\end{array}$ & $\begin{array}{l}\text { City of } \\
\text { Helsinki } \\
\text { EV users } \\
\text { Charging } \\
\text { service } \\
\text { provider }\end{array}$ \\
\hline Designer & $\begin{array}{l}\text { Control } \\
\text { Things }\end{array}$ & $\begin{array}{l}\text { Aalto } \\
\text { University }\end{array}$ & $\begin{array}{l}\text { Control } \\
\text { Things }\end{array}$ & $\begin{array}{l}\text { Aalto } \\
\text { University }\end{array}$ \\
\hline $\begin{array}{l}\text { Inter- } \\
\text { mediary }\end{array}$ & & $\begin{array}{l}\text { Helsinki } \\
\text { Region } \\
\text { Infoshare }\end{array}$ & & $\begin{array}{l}\text { City of } \\
\text { Helsinki }\end{array}$ \\
\hline
\end{tabular}

\subsection{Ideators, Designers and Intermediaries in Iot ecosystem value creation}

The cross-case analysis revealed patterns in the roles of the different actors in the IoT ecosystems. The roles can be linked back to the aforementioned service exchange logic for each role. There was also a pattern in terms of the assumed role and digital layer. In terms of participant motivations, the boundaries were less definite.

The ideators in every use case represented the end users or customers of the services, namely the actors for whom the ecosystem based system level service (SOS) was developed. These actors volunteer their data to the ecosystem, and thus provide one-way knowledge flow from them to the IoT ecosystem in exchange for added value. This value can be monetary, like in the case of EV charging stations, who benefit from the network effects of being a part of the $\mathrm{BnB}$ platform, leading to increased visibility and sales. Individual service users, i.e. citizens, benefit from improved service, and later additional services that the platform can scale up to provide. The ideators mainly operate in content and service layers, where the concrete service is consumed, and less technical expertise on its delivery is required. The ideators must perceive enough generated value and be willing to pay for the developed service, for example through annual subscription to the service. Business model implications for commercial parties include new opportunities in terms of channel, value proposition and partnership innovations.

Cities as ideators and intermediaries benefit from increased capability to perform their mandate as public service providers, and thus promote greater citizen satisfaction, cost efficiency and public profile. They further improve citizen perceptions of the city through citizen engagement and participatory development. Cities can also concretely benefit from the accumulated data for future planning purposes and development of additional service on top of the platform by commercial parties. Cities can collect commission for transactions and thus sustain the services, as well as facilitate the further use of the data for commercial parties for a fee.

Other intermediaries in the cases included the public agencies and organizations' IT departments. The public agencies enabled and orchestrated collaboration in the ecosystem in both providing knowledge to the ecosystems and establishing knowledge sharing between separate ecosystems. The technology companies and cities' IT departments enabled collaboration in technical terms, like in the case of the Lyon bottle banks, they enabled the data flow from the banks and trucks to the city traffic 
management system to make decisions to optimize the operation. The major role for these commercially motivated companies was the data integration through standard API to enable interoperability, and on the other hand data analysis for knowledge contextualization for the services. Typical layers were network, device and service layers. Their motivation for the ecosystem participation is the collected data and analytic tools, which enables enormous opportunities for scaling up the innovations and designing additional services. Direct impacts on business models can be achieved in terms of reaching out to new customer segments, channels, and value propositions.

Designers in each IoT ecosystem were represented by commercial actors developing user interfaces and apps for accessing the data. They were compensated for their activities, like Control Things for the EV charging app. They both provided knowledge and received it in reciprocal collaborative relationships with the ecosystems. The added value for the designers in bIoTope-type ecosystems, building on OSS standards, is that they by-pass the dominant commercial technology platforms, and thus provide new opportunities and freedom in service creation. This also opens up new opportunities for niche providers especially in network and device layers, where entry barriers are currently high with required investments.

These companies also benefited from free access to data, which enabled them to develop commercial applications with reduced cost, and opportunities to access a broader customer base. The open standard enabled several paths for scalability and increased profitability through network externalities, and access to new partners and customers, like in the case of Brussels traffic safety, where additional traffic management services could be added. Table 5 summarizes the three roles and their main activities.

Table 5. Summary of roles and activities in loT ecosystems

\begin{tabular}{|l|l|}
\hline Role & Main activities \\
\hline $\begin{array}{l}\text { Ideator } \\
\text { Service layers) }\end{array}$ & $\begin{array}{l}\text { Articulate need } \\
\text { Volunteer data } \\
\text { Consume commercial service }\end{array}$ \\
\hline Designer & $\begin{array}{l}\text { Analyze data } \\
\text { Develop commercial service } \\
\text { Deliver commercial service }\end{array}$ \\
$\begin{array}{l}\text { (Device, Network } \\
\text { and Service layers) }\end{array}$ & \\
\hline Intermediary & $\begin{array}{l}\text { Coordinate activities } \\
\text { Enable access } \\
\text { Control platform }\end{array}$ \\
(Network and & \\
Contents layers) &
\end{tabular}

\section{Discussion and conclusion}

The research question of the paper was: How do different actors contribute to the IoT ecosystem cocreation? We have answered the question by exploring and describing the activities and roles of different IoT ecosystem actors in digital layers. We identified the activities of Ideators, Designers, and Intermediators in three cases and suggested patterns in their activities.

Our paper made several contributions to the understanding of the IoT ecosystem business model components and actor dynamics. Overall, our study provides empirical evidence of the variety of activities that may take place in IoT ecosystem value creation. Thus, we contribute to the IoT ecosystem business model discussion, which has so far been mainly conceptual.

By defining different roles for the ecosystem actors in service co-creation, we extend the discussion on ecosystem business model mapping, which so far has not made explicit the role variation in service cocreation. Service-Dominant logic is essentially about application of capabilities, knowledge and skills for the benefit of the recipient [32], [33], and making sense of the roles provides a better understanding of value co-creation and specific business model options for each role archetypes in business ecosystems.

The finding that ideators are the beneficiaries of the developed services supports the user-driven development paradigm and earlier findings on the emphasized role of user data in service creation. Thus, the IoT ecosystem can be considered an ad hoc alignment structure for the approximation of designer resources and ideator needs for new value creation.

By adding the role variation to the previous contributions with digital layers and motivations of different actors [1], we expanded and advanced the existing discussion on IoT ecosystem business models with the actor objectives. A better understanding of actor drivers clarifies the diversified and unstructured nature of IoT ecosystems, and addresses the challenges identified by earlier literature [8]. The structuring of activities around role archetypes may further the understanding about how ecosystems appear and evolve.

The study supports earlier notions of the relevance of the ecosystem level value proposition discussion [1], [4], [19], [20]. Previous literature on ecosystem business models has emphasized the role of value pillars [8]. Our empirical cases demonstrate how the IoT ecosystem value creation was constructed around shared purpose, which expressed the values they wished to promote by their activities. This is in line with recent ecosystems as structure perspective [27], which argues for the relevance of activities aligned 
according to a value proposition. Mature-open-source software and standards enable further scalability and de-centralization of value creation in the ecosystems, challenging further the early pillar-based views.

Our findings also suggest that cost reduction may not be the explicit shared purpose at IoT ecosystem level, although it is sought for at the level of organizations [4]. Our findings support earlier theorizing [1] that different ecosystem actors may have monetary or non-monetary drivers for their contribution in IoT ecosystem value creation. Excluding non-monetary drivers and contributing activities might overlook relevant parts of the IoT ecosystem.

Our study provides empirical evidence for the earlier argument that value in the IoT context can be created in four layers [1]: device, network, service and content layer [18]. In addition, it adds to the earlier argument that one of the major changes in IoT business models is the change in the role of data [19], [20]. Our study adds to these notions and shows how sensors and analytical capabilities contribute strongly in IoT ecosystem value creation.

We extend the previous conceptualizations of the IoT ecosystem business model [1], [8]. The combining of the digital layers and service co-creation roles captures the key elements of IoT ecosystem business model discussion (Who? Why? Where?). By looking at a business model as activities of different service cocreation actors we suggest that IoT ecosystem business models be defined as internet mediated activities among the service co-creation actors and connected smart objects, aligned for creating and capturing value both for each role in service exchange and for a shared purpose.

\section{Managerial contribution}

The study offers insights for planning and management of IoT ecosystems. The detailed descriptions of the activities related to roles of Ideators, Designers, and Intermediaries also makes explicit the points at which and what kind of managerial practices are needed.

Increased awareness of the different roles supports participating firms' IoT ecosystem strategy planning and visualization of business opportunities. The illustration of the ecosystem business model creates an opportunity for shared sense-making, thus acting as a cognitive tool for business model design. Thus, it can provide firms a conceptual tool [7], [17] for orchestrating the activities among the different actors and e.g., reduce inefficiencies in the IoT ecosystem.

Application of the SD-Logic to IoT ecosystems can provide highly relevant avenues. Lusch \&
Nambisan [26] argue that in service co-creation, it is necessary not only to define the roles but also to create supportive environments for integration of resources. According to them, this can be done by "focusing on (1) mechanisms that facilitate interactions among diverse actors, (2) adapting internal processes to accommodate different actors (roles), and (3) enhancing the transparency of resource integration activities in the service ecosystem."[26]. This kind of ecosystem mapping can be a valuable tool for ecosystem actors as an architecture or strategy of participation [26], as well as design of future IoT ecosystems and interfaces.

\section{Limitations \& further research}

As with any research, this study has limitations. For generalization of the identified roles and their activities, other cases in different contexts could further the generalizability of the results. The increasing interest in the Iot in a smart city context lays opportunities for future research in this area. Other avenues for further research can be found in IoT ecosystems operating in different contexts, such as smart agriculture. From a methodological perspective, future research could benefit from e.g., simulations [40] for evaluating IoT ecosystem business models.

Further, the study is limited by the fact that the studied IoT ecosystems are in their early phases where the focus is predominantly on products rather than processes and business models. Therefore, a longitudinal analysis of the evolution of the IoT ecosystem business models would be beneficial for furthering the discussion.

\section{Acknowledgements}

The bIoTope project and this research have received funding from the European Commission.

\section{References}

[1] S. Turber et al, "Designing business models in the era of internet of things," in Int. Conference on Design Science Research in Information Systems, 2014, pp. 17-31.

[2] ITU, "SERIES Y: GLOBAL INFORMATION

INFRASTRUCTURE, INTERNET PROTOCOL ASPECTS AND NEXT-GENERATION NETWORKS-

Frameworks and functional architecture models," International Telecommunication Union, Geneva, Recommendation ITU-T Y, vol. 2060, 2012.

[3] K. Främling et al, "Product agents for handling information about physical objects," Report of Laboratory of Information Processing Science Series B, TKO-B, vol. 153, (03), 2003. 
[4] R. Dijkman et al, "Business models for the Internet of Things," Int.J.Inf.Man., vol. 35, (6), pp. 672-678, 2015. [5] L. Atzori, A. Iera and G. Morabito, "The internet of things: A survey," Computer Networks, vol. 54, (15), pp. 2787-2805, 2010

[6] J. Magretta, "Why business models matter," 2002.

[7] B. W. Wirtz et al, "Business models: Origin, development and future research perspectives," Long Range Plann., vol. 49, (1), pp. 36-54, 2016.

[8] M. Westerlund, S. Leminen and M. Rajahonka, "Designing business models for the internet of things," Technology Innovation Management Review, vol. 4, (7), pp. 5, 2014.

[9] M. M. Iivari et al, "Toward ecosystemic business models in the context of industrial internet," J.Bus.Models, vol. 4, (2), pp. 42-59, 2016.

[10] S. Johnson, Emergence: The Connected Lives of Ants, Brains, Cities. New York: Scribner, 2001.

[11] L. Morgan and P. Finnegan, "Deciding on open innovation: An exploration of how firms create and capture value with open source software," in IFIP Working Conference on Open IT-Based Innovation: Moving Towards Cooperative IT Transfer and Knowledge Diffusion, 2008, pp. 229-246.

[12] J. West and S. Gallagher, "Key challenges of open innovation: lessons from open source software," San Jose State College of Business, Mimeo, 2004.

[13] J. West and S. O'Mahony, "Contrasting community building in sponsored and community founded open source projects," in System Sciences, 2005. HICSS'05.

Proceedings of the 38th Annual Hawaii International Conference on, 2005, pp. 196c-196c.

[14] J. West, "Value capture and value networks in open source vendor strategies," in System Sciences, 2007. HICSS 2007. 40th Annual Hawaii International Conference on, 2007, pp. 176-176.

[15] C. Zott, R. Amit and L. Massa, "The business model: recent developments and future research," Journal of Management, vol. 37, (4), pp. 1019-1042, 2011.

[16] P. B. Seddon et al, "The case for viewing business models as abstractions of strategy," The Communications of the Ass. for Information Systems, vol. 13, (1), pp. 64, 2004. [17] A. Osterwalder, Y. Pigneur and C. L. Tucci,

"Clarifying business models: Origins, present, and future of the concept," Communications of the Association for Information Systems, vol. 16, (1), pp. 1, 2005.

[18] Y. Yoo, O. Henfridsson and K. Lyytinen, "Research commentary - the new organizing logic of digital innovation: an agenda for information systems research," Information Systems Research, vol. 21, (4), pp. 724-735, 2010.

[19] G. Hui, "How the internet of things changes business models," Harv. Bus. Rev., vol. 29, 2014.

[20] J. Ju, M. Kim and J. Ahn, "Prototyping Business Models for IoT Service," Procedia Computer Science, vol. 91, pp. 882-890, 2016.

[21] M. Iansiti and R. Levien, "Strategy as ecology," Harv. Bus. Rev., vol. 82, (3), pp. 68-81, 2004.

[22] J. F. Moore, "Predators and prey: a new ecology of competition," Harv. Bus. Rev., vol. 71, (3), pp. 75-83, 1993.
[23] M. Ceccagnoli et al, "Co-creation of value in a platform ecosystem: The case of enterprise software," 2011.

[24] K. Valkokari, "Business, innovation, and knowledge ecosystems: how they differ and how to survive and thrive within them," Technology Innovation Management Review, vol. 5, (8), 2015.

[25] E. Autio and L. Thomas, "Innovation ecosystems,"

The Oxford Handbook of Innovation Management, pp. 204288, 2014.

[26] R. F. Lusch and S. Nambisan, "Service Innovation: A Service-Dominant Logic Perspective." Mis Quarterly, vol. 39, (1), pp. 155-175, 2015.

[27] R. Adner, "Ecosystem as Structure An Actionable Construct for Strategy," Journal of Management, vol. 43, (1), pp. 39-58, 2017.

[28] R. Normann and R. Ramirez, "From value chain to value constellation: designing interactive strategy," Harv. Bus. Rev., vol. 71, (4), pp. 65-77, Jul-Aug, 1993.

[29] C. K. Prahalad and V. Ramaswamy, "The co-creation connection," Strategy and Business, pp. 50-61, 2002.

[30] C. K. Prahalad and V. Ramaswamy, "Co-creating unique value with customers," Strategy \& Leadership, vol. 32, (3), pp. 4-9, 2004.

[31] F. Kohlbacher, "Knowledge-based New Product Development: fostering innovation through knowledge cocreation," International Journal of Technology Intelligence and Planning, vol. 4, (3), pp. 326-346, 2008.

[32] S. L. Vargo and R. F. Lusch, "Service-dominant logic: continuing the evolution," Journal of the Academy of Marketing Science, vol. 36, (1), pp. 1-10, 2008.

[33] S. L. Vargo and R. F. Lusch, "Evolving to a new dominant logic for marketing," J. Market., vol. 68, (1), pp. $1-17,2004$.

[34] A. Smedlund and M. Toivonen, "The role of KIBS in the IC development of regional clusters," Journal of Intellectual Capital, vol. 8, (1), pp. 159-170, 2007.

[35] C. Dhanaraj and A. Parkhe, "Orchestrating innovation networks," Academy of Management Review, vol. 31, (3), pp. 659-669, 2006.

[36] K. M. Eisenhardt and M. E. Graebner, "Theory building from cases: Opportunities and challenges," Academy of Management Journal, vol. 50, (1), pp. 25-32, 2007.

[37] K. M. Eisenhardt, "Building theories from case study research," Academy of Management Review, vol. 14, (4), pp. 532-550, 1989.

[38] S. Kubler et al, "Open IoT Ecosystem for Sporting Event Management," IEEE Access, 2017.

[39] S. C. Lambert and R. A. Davidson, "Applications of the business model in studies of enterprise success, innovation and classification: An analysis of empirical research from 1996 to 2010," European Management Journal, vol. 31, (6), pp. 668-681, 2013.

[40] N. Gilbert and K. Troitzsch, Simulation for the Social Scientist. McGraw-Hill Education (UK), 2005.

[41] M. Tsujimoto et al, "A review of the ecosystem concept-Towards coherent ecosystem design," Technological Forecasting and Social Change, 2017. 